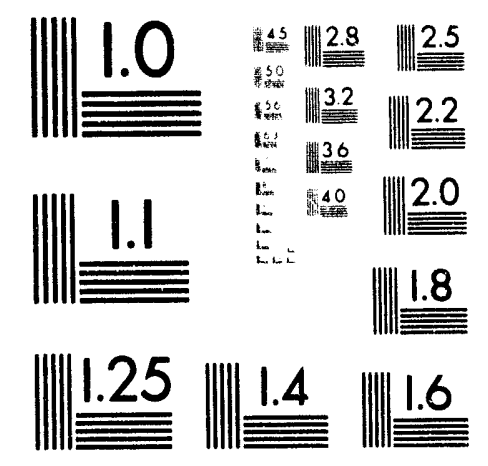



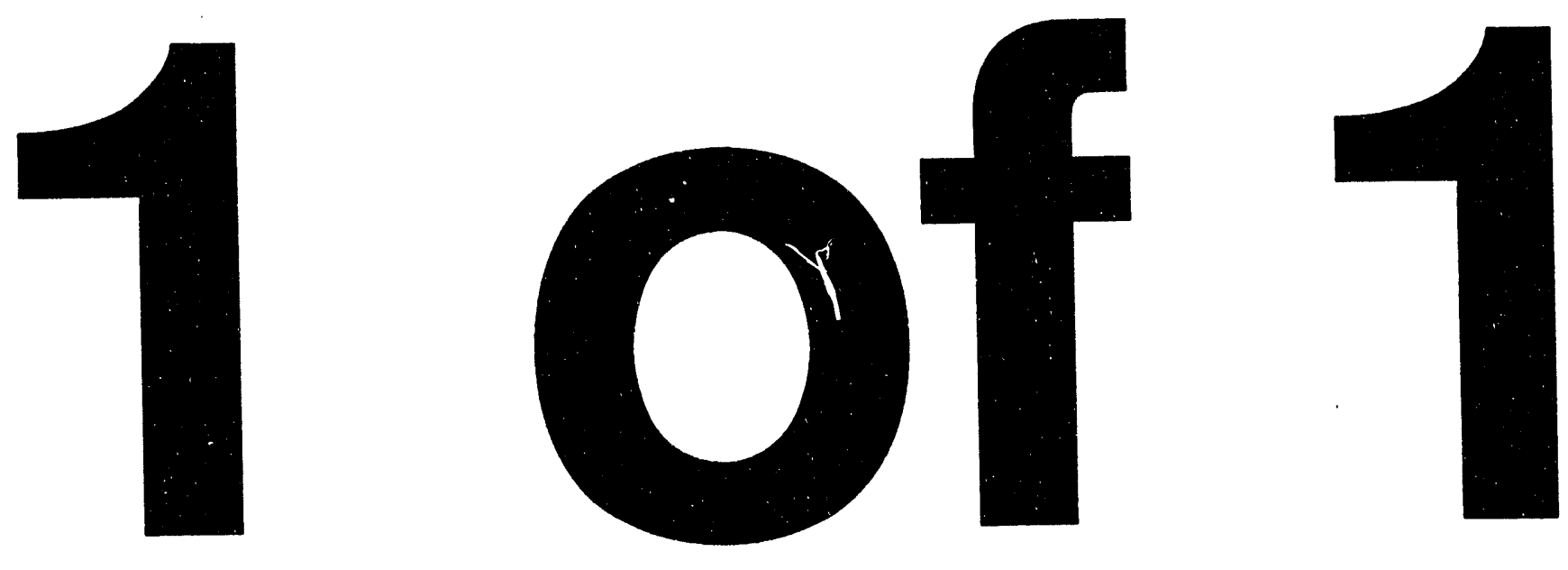


\title{
A SIMPLE DESCRIPTION OF FLOW INSTABILITY WITH APPLICATION TO A PACKED BED
}

\author{
Dean Dobranich \\ Sandia National Laboratories \\ Nuclear Technology Organization 6513 \\ Albuquerque, NM 87185 \\ 505-845-7014
}

\begin{abstract}
A simplified explanation for gas flow instability in parallel heated channels is presented with specific applications to channels containing packed beds of power-producing particles. The explanation captures the basic governing physics of the viscosity-driven instability and hopefully removes some of the misconceptions surrounding this issue. Simple illustrative c.llculations, steady-state and transient, using the SAFSIM computer program are included in the explanation. The explanation points out that flow instability is common to any and all gas flow systems with parallel heated channels, that the addition of flow resistance to the entrance of a channel mitigates flow instability, and that instabilities do not occur instantaneously.
\end{abstract}

\section{INTRODUCTION}

An issue that has received considerable recent attention in the space reactor community is that of flow instability in parallel heated channels (Black, 1993; Witter, 1993; and Kerrebrock, 1993). This issue is not new [references to the issue can be found dated as early as 1938 (Ledinegg, 1938)] but has resurfaced because of the current interest in particle bed reactors (Powell, 1985). Whenever a gas flows between two reservoirs or plenums through parallel heated channels, there exists the potential for flow instability. The result of such an instability is to starve one or more of the channels of gas flow. The direct dependence of gas viscosity on temperature is the dominant contributor to this type of instability, which is often referred to as laminar or viscosity-driven flow instability. This paper provides an engineering explanation of this phenomena with application to a packed bed of power producing particles. This simplified explanation relies on SAFSIM (Dobranich, 1992) calculations for one specific flow system and hopefully provides a qualitative feel for the phenomena. The approach and conclusions of this work are similar to those of Reshotko, 1967; the major difference in the current work is the application to a packed bed. Again, the emphasis of this flow stability primer is on simple examples and is directed to those in the space reactor community with minimum background in fluid mechanics.

\section{ENGINEERING EQUATIONS FOR FLOW INSTABILITY}

The following equation for the pressure drop of the gas in an arbitrary-geometry flow channel serves as the starting point for the explanation of the instability phenomena:

$$
\Delta p=f \frac{l}{d} \frac{G^{2}}{2 \rho}
$$

where $\Delta p$ is the frictional pressure drop, $f$ is the friction factor, $l$ is the channel length, $d$ is a characteristic dimension, $G$ is the mass flux $(\rho v), v$ is the gas velocity, and $\rho$ is the gas density. This equation indicates that the pressure drop is proportional to the square of the mass flux and is based on a simple steady-state momentum balance for flow in a 1-D channel, neglecting kinetic and potential energy. The key to its use is the determination of the friction factor. Empirical correlations for the friction factor have been developed for engineering applications. $\mathrm{A}$ general form of these correlations can be expressed as:

$$
f=\left(\frac{a}{\varepsilon^{3}}\right)\left[c_{1}\left(\frac{a}{R e}\right)^{c_{2}}+c_{3}\left(\frac{a}{R e}\right)^{c_{4}}+c_{5}\right] \text { a }
$$


where $a$ is equal to 1 for pipe flow, and $a$ is equal to $1-\varepsilon$ for porous media (packed bed) flow, $\varepsilon$ is the bed porosity ( 1 for pipe flow), $c_{1}, c_{2}, c_{3}, c_{4}$, and $c_{5}$ are constants (see Table 1), Re is the superficial Reynolds number $(\varepsilon \mathrm{Gd} / \mu)$, and $\mu$ is the dynamic viscosity of the gas.

The Reynolds number in these equations is based on the superficial flow area, which is the flow area if the channel did not have any particles in it. For pipe flow, the porosity is equal to 1 and the characteristic dimension in the Reynolds number is the pipe diameter. For a channel containing a packed bed of particles, the characteristic dimension is the particle diameter. Table 1 provides the values of the constants appearing in Equation (2) for different flow situations. These correlations can be found in Chapman, 1987 for pipe flow and in Macdonald, 1979 and Achenbach, 1982 for the packed bed flows.

Table 1. Friction Factor Correlation Constants

\begin{tabular}{|l|l|c|c|c|c|c|c|}
\hline & \multicolumn{1}{|c|}{} & \multicolumn{7}{c|}{ Constants } \\
\hline Correlation & \multicolumn{1}{|c|}{ Comments } & $a$ & $c_{1}$ & $c_{2}$ & $c_{3}$ & $c_{4}$ & $c_{5}$ \\
\hline $\begin{array}{l}\text { Laminar Pipe } \\
\text { Flow }\end{array}$ & $\begin{array}{l}\text { Re }<2,300 \\
\text { (theoretical) }\end{array}$ & $\begin{array}{c}1 \\
(\varepsilon=1)\end{array}$ & 64 & 1 & 0 & 0 & 0 \\
\hline $\begin{array}{l}\text { Turbulent Pipe } \\
\text { Flow }\end{array}$ & $\begin{array}{l}4,000<\operatorname{Re}<50,000 \\
\text { (smooth surface) }\end{array}$ & $\begin{array}{c}1 \\
(\varepsilon=1)\end{array}$ & 0.316 & 0.25 & 0 & 0 & 0 \\
\hline $\begin{array}{l}\text { Turbulent Pipe } \\
\text { Flow }\end{array}$ & $\begin{array}{l}30,000<\text { Re }<10^{6} \\
\text { (smooth surface) }\end{array}$ & $\begin{array}{c}1 \\
(\varepsilon=1)\end{array}$ & 0.184 & 0.2 & 0 & 0 & 0 \\
\hline Ergun & Packed Bed Flow & $1-\varepsilon$ & 300 & 1 & 0 & 1 & 3.5 \\
\hline Modified Ergun & $\begin{array}{l}\text { Packed Bed Flow } \\
\text { (smooth surface) }\end{array}$ & $1-\varepsilon$ & 360 & 1 & 0 & 1 & 3.6 \\
\hline Modified Ergun & $\begin{array}{l}\text { Packed Bed Flow } \\
\text { (rough surface) }\end{array}$ & $1-\varepsilon$ & 360 & 1 & 0 & 1 & 8 \\
\hline Achenbach & Packed Bed Flow & $1-\varepsilon$ & 320 & 1 & 20 & 0.4 & 1.75 \\
\hline
\end{tabular}

For laminar pipe flow, the pressure drop can be shown to be proportional to the product of mass flux and viscosity. For turbulent pipe flow, the pressure drop is proportional to the mass flux raised to the 1.8 power times the viscosity raised to the 0.2 power. A key to the flow instability issue is the temperature dependence of the viscosity; for a gas, viscosity increases with increasing temperature. Similar pressure drop dependencies for flow in packed beds can also be derived using the same equations but different friction factor constants $\left(c_{1}-c_{5}\right)$; however, it is instructive to demonstrate these dependencies graphically, as follows.

\section{SAFSIM CALCULATION RESULTS}

The next five subsections provide a description of results based on SAFSIM calculations. The first four subsections deal with steady-state calculations and the fifth subsection deals with transient calculations. SAFSIM is a general-purpose computer program that provides steady-state and transient solutions of the onedimensional compressible flow equations for a user-specified flow network. Thus SAFSIM is simultaneously solving a mechanical [approximated by Equation (1)] and a thermal energy equation. The thermal energy equation requires that the energy generated equal the energy added to the gas at steady state.

\section{Single Channel}

To investigate Equation (1), a SAFSIM input model of a single flow channel was prepared. The channel is assumed to be $1 \mathrm{~cm}$ long and to contain a packed bed with a uniform porosity of 0.4 . The bed is comprised of spherical particles having a diameter of $400 \mu \mathrm{m}$. The channel has a square cross section, $1 \mathrm{~cm}$ by $1 \mathrm{~cm}$, resulting in a superficial flow area of $10^{-4} \mathrm{~m}^{2}$. An exit pressure of $7.58 \mathrm{MPa}$ and an inlet hydrogen gas temperature of $125 \mathrm{~K}$ are also assumed. The exterior of the channel is assumed to be insulated. The Ergun equation for the friction factor correlation was selected because it is a well known correlation for flow in packed beds. Also, the Achenbach correlation for the heat transfer coefficient is used. It should be noted that the following calculations could have been performed for flow in a heated pipe with similar results. 
For simplicity, constant values of specific heat $\left(1.5 \cdot 10^{4} \mathrm{~J} / \mathrm{kg}-\mathrm{K}\right)$ and thermal conductivity $(0.2 \mathrm{~W} / \mathrm{m}-\mathrm{K})$ are assumed for the hydrogen gas. Also, the effective bed conductivity of $2 \mathrm{~W} / \mathrm{m}-\mathrm{K}$ is assumed to be independent of temperature. Hydrogen density is based on the ideal gas law and the temperature dependence of the dynamic viscosity of the gas is approximated by the following equation:

$$
\mu=2 \cdot 10^{-7} \cdot T^{2 / 3}
$$

where $\mu$ is the viscosity in $\mathrm{Pa} \cdot \mathrm{s}$, and $T$ is the gas temperature in $\mathrm{K}$.

Figure 1 provides the steady-state channel pressure drop as a function of superficial mass flux for three different bed power densities (power density is uniform within the bed). For the case with no internal power generation, the curve indicates, as expected, that the pressure drop decreases to zero as the mass flux decreases to zero. However, if there is power generation within the channel, a minimum value of pressure drop occurs. The mass flux at which this minimum occurs is referred to as the critical mass flux. (The portion of the curve with negative slope is usually associated with laminar flow in which pressure drop is dominated by viscous effects. The portion of the curve with positive slope is associated with turbulent flow in which pressure drop is dominated by inertial effects. More precisely, a transition region exists in the neighborhood of the minimum that is a combination of both laminar and turbulent flow.) The critical mass flux increases as the power density increases. The critical mass flux value, as will be-

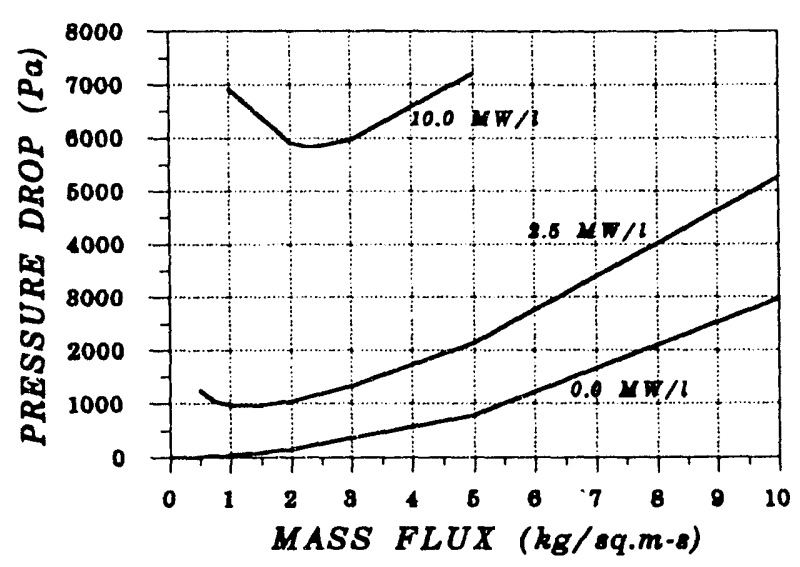

Figure 1. Channel Pressure Drop Characteristic Curves come clear as this explanation progresses, governs the flow stability. A flow system with a low critical mass flux provides more margin with respect to stability.

The fact that the minimum mass flux for a channel with no power generation is zero suggests that adding a flow resistance to a power-generating channel will reduce the critical mass flux while increasing the pressure drop of the channel. Figure 2 shows the pressure drop for the channel in which a cold frit was added to the entrance of the packed bed. The bed has a power density of $2.5 \mathrm{MW} / \mathrm{L}$ but the cold frit has no internal power generation. The cold frit was modeled as a packed bed with additional resistance in the form of added $l / d$. As expected, the larger the cold frit resistance, the smaller the critical mass flux.

\section{Two Channels}

So far, only a single channel has been studied.

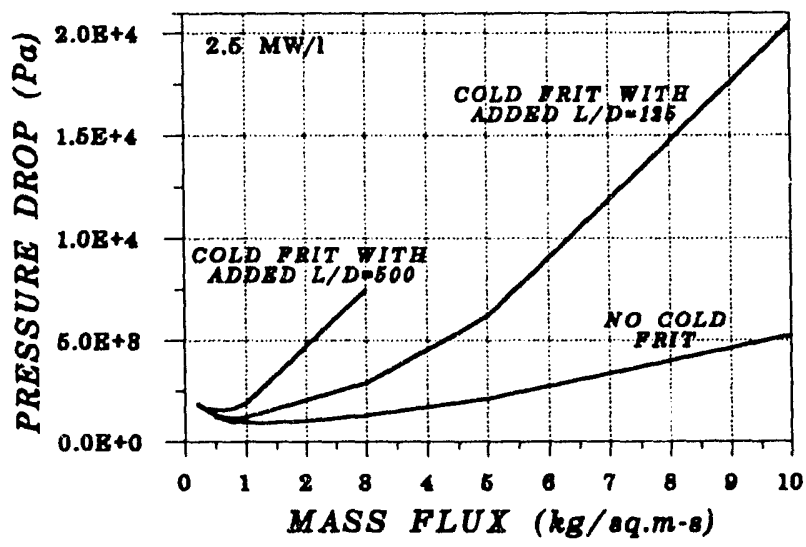

Figur: 2. Pressure Drop Characteristic Curves With an Added Cold Frit (2.5 MW/L)

But it takes multiple channels with different pressure drop characteristics for a flow stability problem to arise if the mass flow rate is specified as a boundary condition to an inlet plenum. (Flow instability in a single channel can occur if pressure is the specified inlei boundary condition. However, the focus of this paper is on instability in multiple channels, which is best investigated using a mass flow rate boundary condition). Figure 3 shows the pressure drop curves for a channel with porosity of 0.4 and for another identical channel except the porosity has been decreased to 0.38 . (The porosity values were selected simply for illustrative purposes.) The lower 
porosity channel is more restrictive to flow and has a slightly higher critical mass flux value. The pressure drop characteristics of a channel could also be changed, for example, by changing the particle diameter, the channel length, the power density, or by the introduction of a localized flow blockage.

A new SAFSIM input model was created with two parallel-flow channels connected between two common plenums; the entrance plenum has twice the superficial flow area as a single channel. If the channels are identical, and nothing happens to change the pressure drop characteristics of the channels (such as the occurrence of a local flow blockage), then no redistribution of flow occurs, independent of power density and mass flux. The flow simply splits evenly between the channels. If the pressure drop characteristics of the two channels are different, a redistribution of flow between the two channels occurs. To investigate this, the porosity of one channel was set to 0.4 and the other to 0.38 in the two-channel input model. Neither channel ir cluded a cold frit. (The analyses to follow could have been performed by changing the power density, particle diameter, or length of one of the channels with analogous results.)

Figure 4 shows how the pressure drop curves

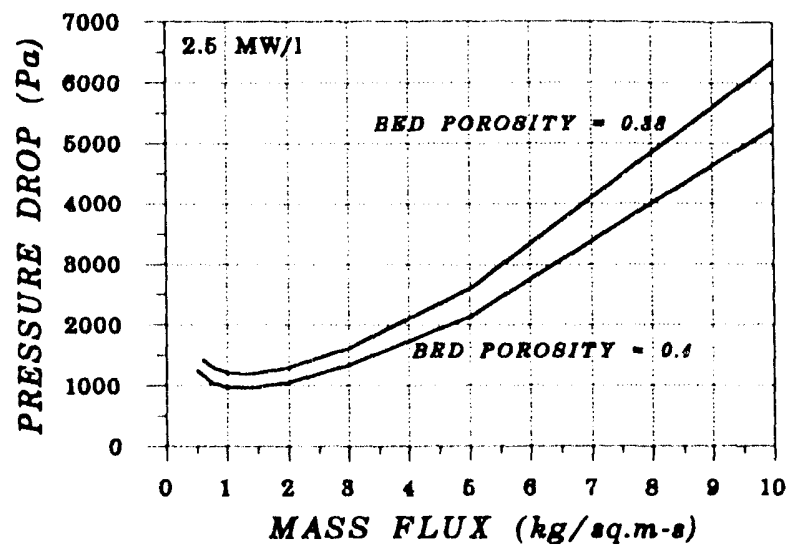
for the two channels can be used graphically to determine the redistribution of flow. For the two-channel system, two conditions must be satisfied: (1) the pressure drop across both channels must be identical because they are connected to the same inlet arid outlet rescrvoirs, and (2) the sum of the two channel mass flow rates must equal the total mass flow rate (conservation of mass). For a total mass flow rate of $3.7 \cdot 10^{-4} \mathrm{~kg} / \mathrm{s}$, these two conditions are met if the mass flux in the 0.38 porosity channel is $1.2 \mathrm{~kg} / \mathrm{m}^{2}$-s (a flow rate of $1.2 \cdot 10^{-4} \mathrm{~kg} / \mathrm{s}$ ) and the mass flux in the 0.4 porosity channel is $2.5 \mathrm{~kg} / \mathrm{m}^{2}$-s (a llow rate of $2.5 \cdot 10^{-4}$ $\mathrm{kg} / \mathrm{s})$. If the total mass flow rate is greater than $3.7 \cdot 10^{-4} \mathrm{~kg} / \mathrm{s}$, the different pressure drop charac-teristics of the two channels dictates a different, but stable, flow split. If the flow rate is decreased below $3.7 \cdot 10^{-4} \mathrm{~kg} / \mathrm{s}$, an instability is initiated.

The instability can be explained simplisticly as follows. When the flow is laminar (the negativeslope region of the characteristic curve), a decrease in flow rate results in an increase in temperature. This increases the gas viscosity, which in tum increases the flow resistance. Thus less flow goes to this channel, and more flow goes to

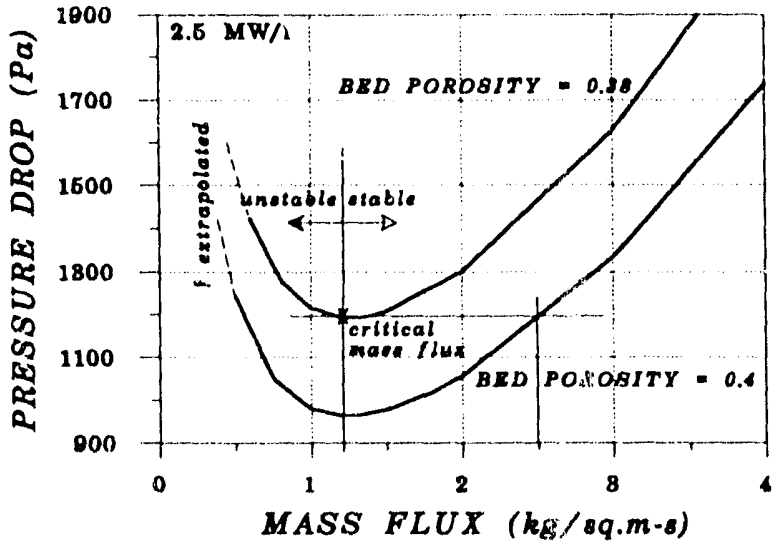

Figure 4. Graphical Solution of Twc- Shannel Flow Redistribution (2.5 MW/L) the other less restrictive channel, which decreases in temperature. As a result, the 0.38 yrosity channel becomes even more restrictive to flow while the 0.4 porosity channel becomes less restrictive. This positive feedback response continues with the net result being that the 0.38 porosity channel is starved of flow and the bed temperatures increase until melting.

- Instability (viscosity driven): an unbounded flow redistribution that results in flow starvation and excessive temperatures in one or more channels of a multichannel flow systern. 
It is important to understand the temperature response of the packed beds in the two channels. If the flow decreases in a channel, the temperature must increase. The temperature response of the two channels is provided in Figure 5 as a function of the inlet mass flux (the sum of the mass fluxes of the two channels). An increase in gas temperature increases the gas viscosity, which increases the channel flow resistance and drives the flow redistribution. At an inlet mass flux of $1.85 \mathrm{~kg} / \mathrm{m}^{2}$-s (a flow rate of $3.7 \cdot 10^{-4} \mathrm{~kg} / \mathrm{s}$ ), the mass flux in the 0.38 porosity channel drops below the critical mass flux $\left(1.2 \mathrm{~kg} / \mathrm{m}^{2}-\mathrm{s}\right)$ and a runaway temperature response is initiated. Therefore, it is important to maintain the mass flux above the critical mass flux of the most restrictive channel. The critical mass flux is a good measure of the flow instability threshold.

Even if the mass flux remains above the critical value, the resulting flow distribution may be such

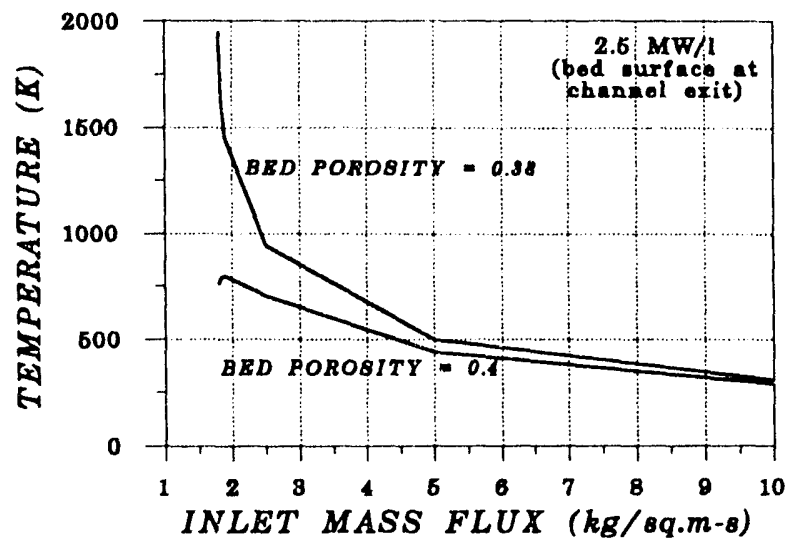

Figure 5. Temperature Response for a Two-Channel Flow System

that the maximum-allowed temperature is exceeded in a channel. In addition to flow instability, the flow maldistributions that occur in multiple channel systems is also of great concern. Any power producing system with multiple flow channels should be designed to minimize flow maldistributions in order to make optimum use of the coolant and to reduce the possibility of flow instability caused by inherent geometry perturbations (such as porosity or power variations).

Maldistribution: an unfavorable, but stable, flow redistribution that results in elevated temperatures in one or more channels of a multichannel flow system.

It is important to note that the results presented so far are applicable only to the assumed $1-\mathrm{cm}$ long channels. Every different channel has a different pressure drop characteristic and therefore has a different critical mass flux and flow redistribution response.

\section{Effect of Axial Conduction}

In the two-channel system addressed so far, the two channels are assumed to communicate only at the common inlet and outlet plenums of the channels. This simplifies the analysis by allowing 1-D flow and conduction calculations. To be more representative of two interconnected channels, the two packed bed channels should be allowed to communicate axially. Thus gas can flow and heat can conduct axially between the two channels. It will now be shown that using a 1-D analysis is a conservative approximation for the twochannel problem for predictions of stability.

Based on the calculated pressure distributions in the two different-porosity channels at a mass flux of $1.2 \mathrm{~kg} / \mathrm{m}^{2}-\mathrm{s}$, the radial (in the direction of flow) and axial pressure gradients were determined and are plotted in Figure 6 (the channel entrance is at the $10 \mathrm{~mm}$ position and so flow is from right to left on the figure). As is evident, the radial gradients are much larger than the axial gradient. Thus flow is predominately in the radial direction and $1-D$ in nature. There is very little axial flow because there is very little driving pressure potential in that direction.

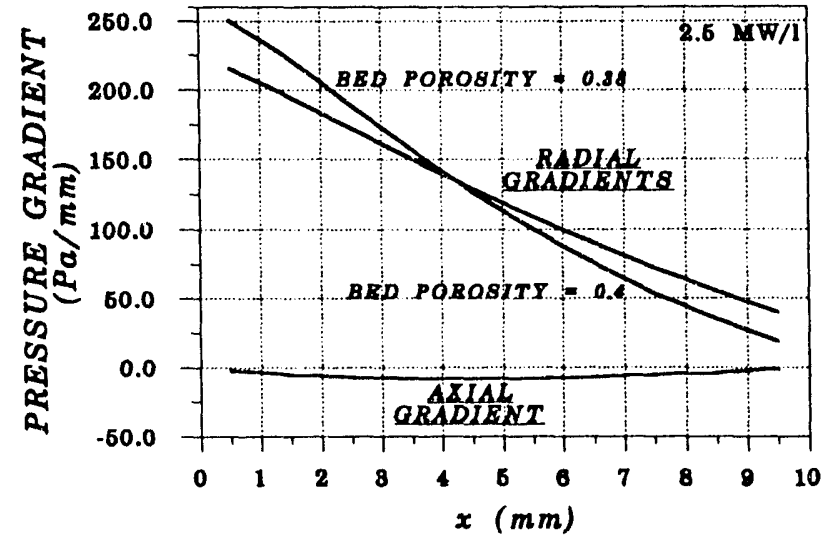

Figure 6. Pressure Gradients in the Two Channels 
The corresponding calculated temperature gradients are shown in Figure 7. The axial temperature gradients are of the same order of magnitude as the radial gradients, which indicates that axial conduction may be significant. Although cumbersome, it is possible to perform 2-D conduction with SAFSIM. The two-channel model was modified to include axial conduction between the two channels, again using a constant bed conductivity of $2 \mathrm{~W} / \mathrm{m} \cdot \mathrm{K}$ and a gas conductivity of 0.2 $\mathrm{W} / \mathrm{m}-\mathrm{K}$ (assumed values). The bed surface temperature distribution results are shown in Figure 8. As expected, the addition of axial conduction decreases the difference in temperature between the two channels. In fact, inclusion of axial conduction serves to increase the stability of the system. Thus further reductions in flow can be made before flow instability occurs. For the twochannel problem, the flow can be reduced by about $2 \%$ compared to the no-axial conduction case. Thus neglecting axial conduction is conservative with respect to predicting flow stability and reinforces the use of the 1-D modeling assumption. Also, calculations using a 2-D computer program, F2D (Suo-Anttila, 1993), demonstrate similar conclusions regarding the conservativeness of 1-D calculations. Similar conclusions are also documented in Witter, 1993 in which multiimensional calculations are compared to 1-D calculations.

A unique feature of the packed bed flow system is that dispersive effects in the bed enhance the gas conductivity in all directions. Though not included in the simple calculations of this work, the dispersive effects have been found (Kerrebrock, 1993; and Suo-Anttila, 1993) to increase the stability of the system in the same manner as inclusion of axial conduction in the two-channel problem. Heat conducts away from the hot spots.

\section{Stability Maps}

Because the critical mass flux is a convenient measure of flow stability, it is useful to plot the critical mass flux as a function of power density. This is done in Figure 9 for the 0.4 porosity channel. Operation of a multichannel system, with this porosity, at conditions to the left of the curve can be interpreted as stable flow conditions. As long as the mass flux falls on this side, flow instabilities will not develop. Another useful curve is shown in Figure 10. This figure shows the

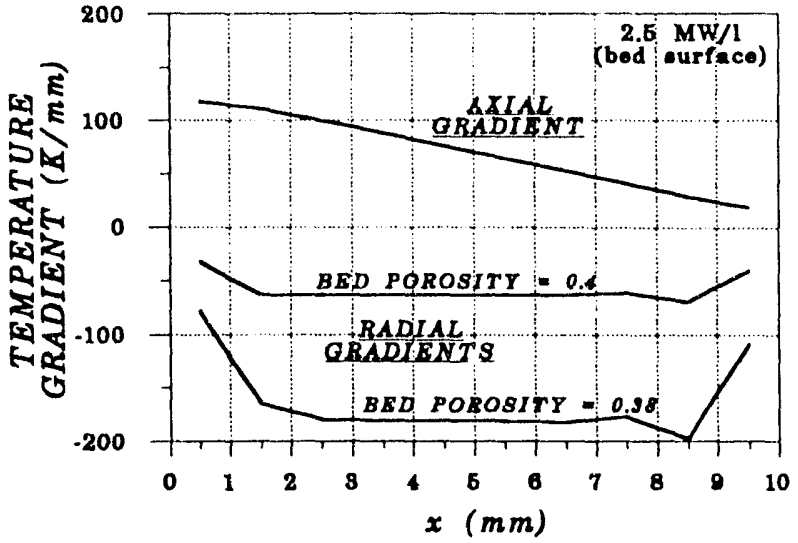

Figure 7. Temperature Gradients in the Two Channels

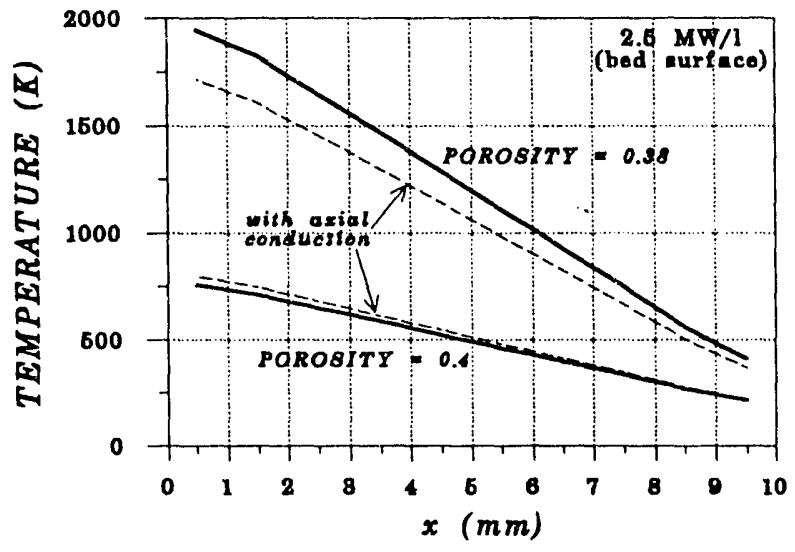

Figure 8. Temperature Distributions With Axial Conduction Included

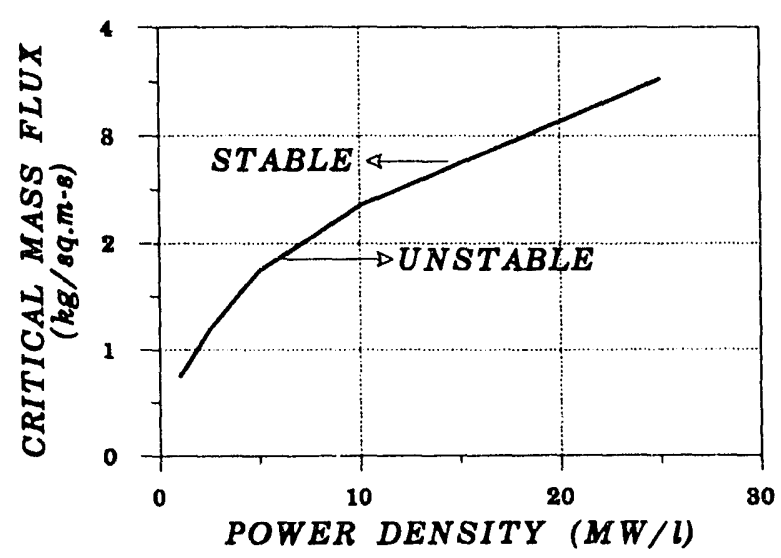

Figure 9. Critical Mass Flux Stability Regimes (Two-Channel System) 
temperature ratio as a function of power density for the 0.4 porosity channel. The temperature ratio is the ratio of the channel gas temperature difference to the channel inlet temperature. Operation of the two-channel system at conditions to the left of this curve can be considered to be unstable. This figure implies that increasing the inlet gas temperature increases the flow stability.

It is important to recognize that these curves do not apply directly to the stability of a particle bed element. Every different fuel element design will have a different stability map. Whether or not introduction of a local flow perturbation (such as a local flow blockage or change in power density) will initiate flow instability depends on how much the local perturbation changes the pressure drop characteristics relative to the unperturbed part of the fuel element. Also, the addition of resistance to the entrance of the channels alters the stability map such that stability is enhanced.

\section{Transient Simulation of Instability Growth}

The analysis so far has been based on steadystate calculations. It is important to understand that flow instabilities and maldistributions do not occur instantaneously. A transient calculation, using the SAFSIM two-channel model with a uniform power density of $2.5 \mathrm{MW} / \mathrm{L}$, was performed in which the mass flow rate was deliberately ramped down in $5 \mathrm{~s}$ to a value below the minimum value required for stable operation, based on steady-state stability criteria. A plot of the flow rate in the two channels as a function of time is provided in Figure 11. Figure 12 shows the bed surface temperature at the channel exits for the transient. The flow redistribution between channels develops slowly and a temperature excursion does not begin until about $80 \mathrm{~s}$. This delay is important to note because it means that a particle bed reactor, or any reactor, can be operated in the unstable regime for a certain length of time without adverse consequences. Although different flow rate and porosity perturbations affect the instability growth rate, the length of time a reactor can be operated in the unstable regime depends primarily on its power density and its heat capacity.

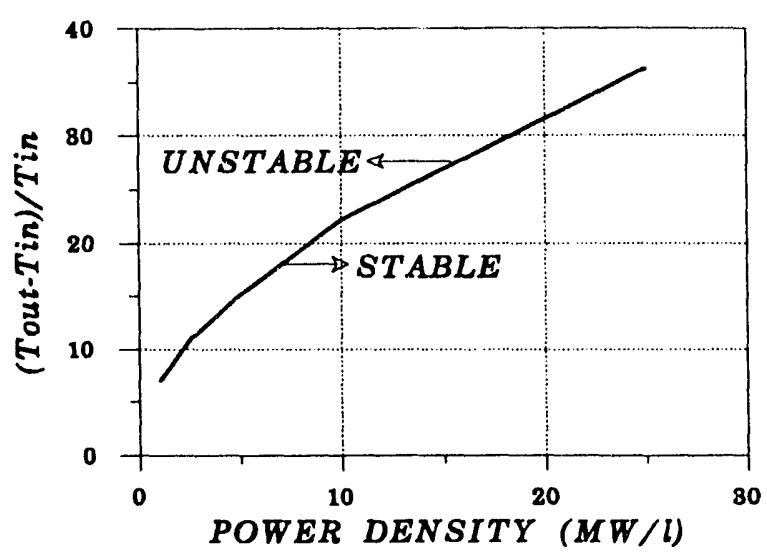

Figure 10. Temperature Ratio Stability Regimes (Two-Channel System)

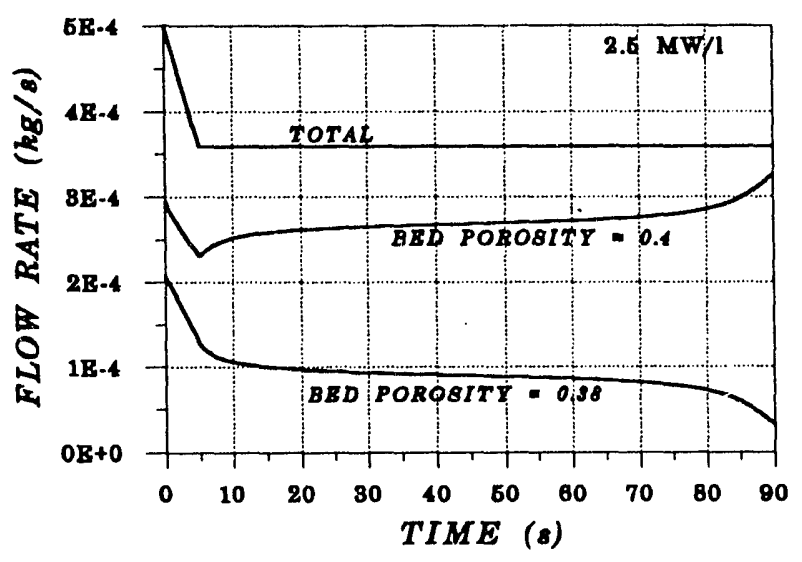

Figure 11. Mass Flow Rate for a Flow Redistribution Transient (Two-Channel System)

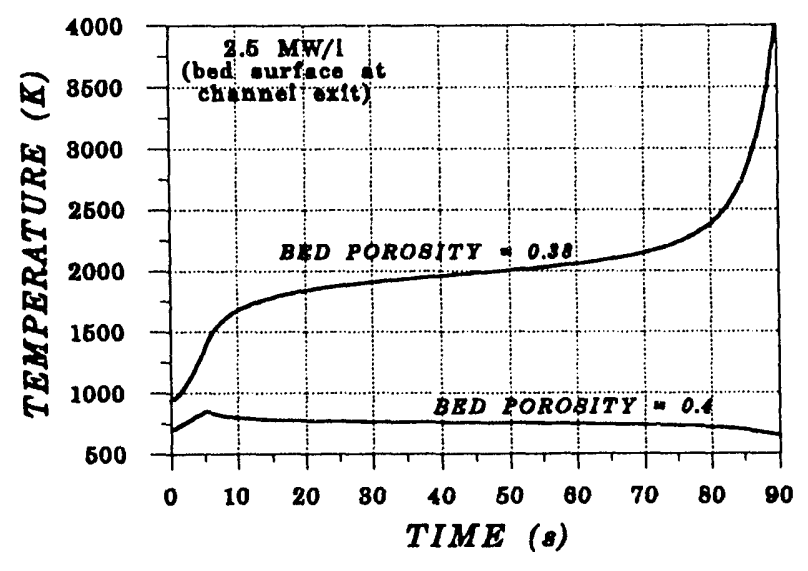

Figure 12. Bed Temperature for a Flow Redistribution Transient (Two-Channel System) 


\section{CONCLUSIONS}

A simplified explanation for gas flow instability in channels containing packed beds of power-producing particles was presented. Based on 1-D calculations, flow stability was demonstrated to depend on the miass flux at which the channel pressure drop is a minimum. This mass flux is called the critical mass flux. The equations that govern pressure drop in a channel are independent of whether the channels are empty (pipe flow) or filled with a porous media. Only the constants in the equation for friction factor change, which does not affect the basic nature of the response. Flow instability is not particular to particle bed systems but instead is a phenomenon common to any and all gas flow systems with multiple heated channels. The calculations also demonstrate that the addition of flow resistance (such as a cold frit) to the entrance of the channels helps to mitigate instability. Additional calculations indicate that axial conduction (perpendicular to the flow) in the bed and gas also mitigates flow instability. Thus dispersive effects that enhance gas conductivity should also be beneficial with respect to stability; this is a unique aspect of flow in channels with packed beds. Finally, transient calculations demonstrate that instabilities do not occur instantaneously. The time for an instability to develop depends on the power density and heat capacity of the bed. Because of the time delay, nuclear reactors can be operated in the unstable flow region for a certain length of time without adverse consequences. Although the explanation for flow insiability offered in this paper is greatly simplified, it captures the basic features of the governing physics and hopefully contributes to a general understanding of the phenomena.

\section{Acknowledgments}

Work described in this paper was funded by the Air Force Space Nuclear Thermal Propulsion Program. This work, performed at Sandia National Laboratories, Albuquerque, NM, was supported by the U.S. Department of Energy under contract DE-AC04-76DP00789.

\section{References}

Achenbach, E., "Heat Transfer and Pressure Drop of Pebble Beds Up to High Reynolds Number," in Proceedings of Seventh International Heat Transfer Conference, Munchen, Germany, pp. 3 - 8, 1982.

Black, David L., "Laminar Flow Instability in Nuclear Rockets," in Proceedings of the $10^{\text {th }}$ Symposium on Space Nuclear Power and Propulsion, CONF-930103, M. S. El-Genk and M. D. Hoover, eds., American Institute of Physics, New York, Conference Proceedings No. 271, 3: 1535 - 1540, January 1993.

Chapman, Alan J., Fundamentals of Heat Transfer, Macmillan Publishing Company, 1987.

Dobranich, Dean, "SAFSIM Input Manual -- A Computer Program for the Engineering Simulation of Flow Systems," Sandia National Laboratories, Albuquerque, NM, SAND92-0694, September 1992.

Kerrebrock, Jack L., and J. Kalamas, "Flow Instability in Particle Bed-Nuclear Nuclear Reactors," presented at 29th AIAA/SAE/ ASME/ASEE Joint Propulsion Conference, June 28-30, 1993.

Ledinegg, M., "Instability of Flow During Natural and Forced Circulation," Die Warme 61, pp. 891-898, 1938.

Macdonald, I. F., M. S. El-Sayed, K. Mow, and F. A. L. Dullien, "Flow through Porous Media - the Ergun Equation Revisited," in Ind. Eng. Chem. Fundam., Vol. 18, No. 3, pp. 199 - 208, 1979.

Powell, J. R., and F. L. Horn, "High Power Density Reactors Based on Direct Cooled Particle Beds," in Space Nuclear Power Systems, M. S. El-Genk and M. D. Hoover, eds., (Malabar, Florida: Orbit Book Co., 1985).

Reshotko, Eli, "An Analysis of the 'Laminar Instability' Problem in Gas-Cooled Nuclear Reactor Passages," AIAA Journal Vol. 5, No. 9, September 1967.

Suo-Anttila, Ahti, "F2D: A Two Dimensional Compressible Gas Flow Code," in Proceedings of the $10^{\text {th }}$ Symposium on Space Nuclear Power and Propulsion, CONF-930103, M. S. El-Genk and M. D. Hoover, eds., American Institute of Physics, New York, Conference Proceedings No. 271, 3: 1673 - 1682, January 1993.

Witter, Jonathan K., David D. Lanning, and John E. Meyer, "Flow Stability Analysis of a Particle Bed Reactor Fuel Element," in Proceedings of the 10 1 Symposium on Space Nuclear Power and Propulsion, CONF930103, M. S. El-Genk and M. D. Hoover, eds., American Institute of Physics, New York, Conference Proceedings No. 271, 3: 1541 - 1546, January 1993. 

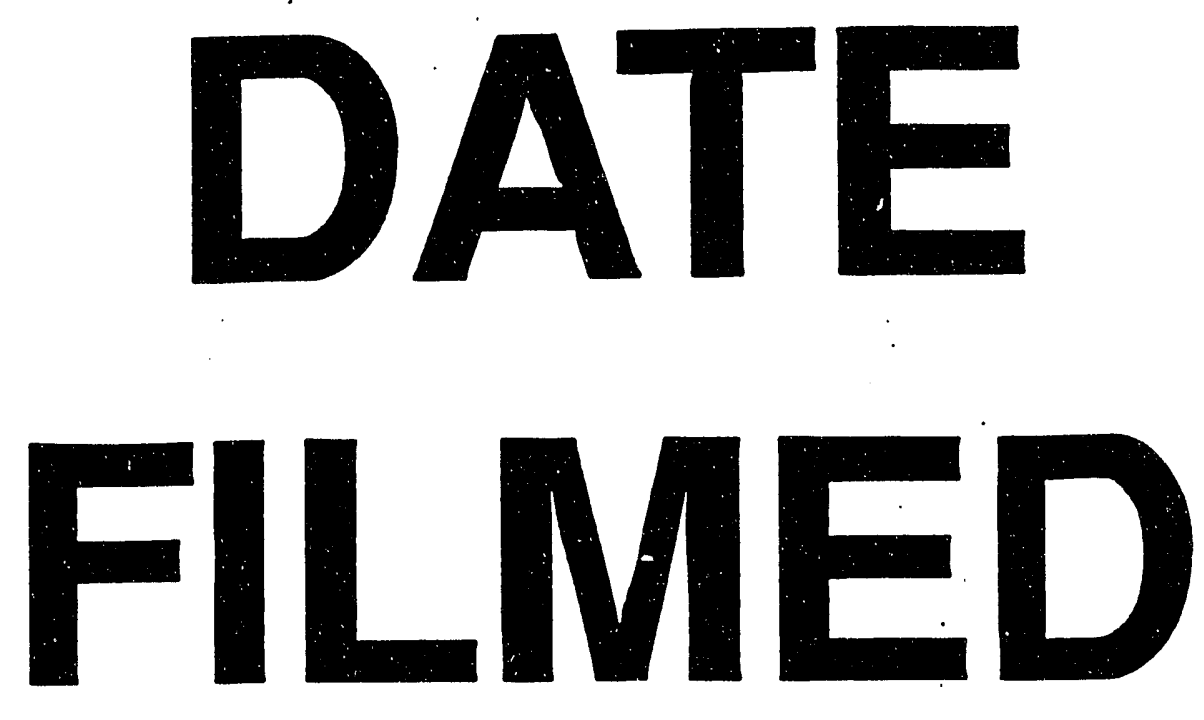

$10 / / 4 / 93$
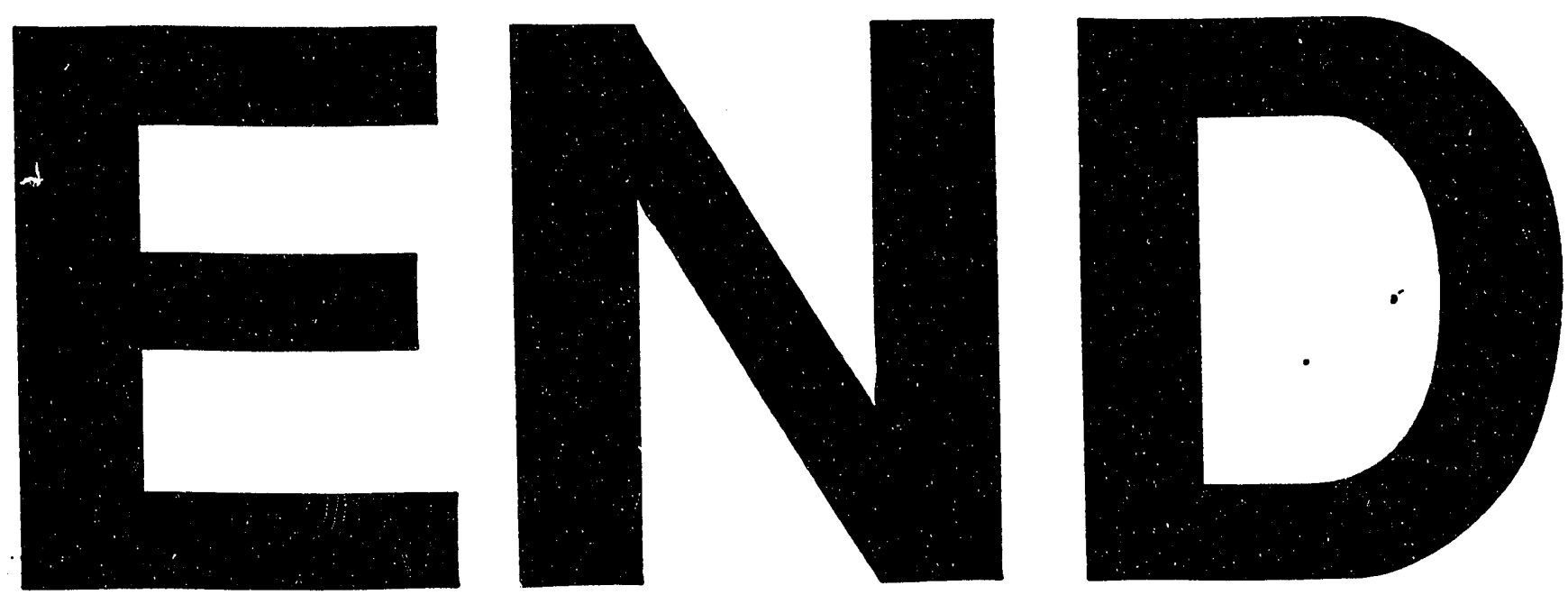
